\title{
Correction to: Health, Safety and Well-Being of Workers in the Informal Sector in India
}

\author{
Sigamani Panneer, Sanghmitra S. Acharya and Nagarajan Sivakami
}

\section{Correction to:}

S. Panneer et al. (eds.), Health, Safety and Well-Being

of Workers in the Informal Sector in India, https://doi.org/10.1007/978-981-13-8421-9

In the original version of the book, the following corrections have been made:

The author name "Smirtima Diksha Lama" has been changed to "Smritima Diksha Lama" in the Chapter "Casualisation and Tea Plantation Labour in India: Does Fair Trade Ensure 'Fairness' in a Plantation System?”.

The author name "Nemethianngai Guite" has been changed to "Nemthianngai Guite" in the Chapter "Occupational Health Issues in Funeral Work: A Study of Dom Caste in Varanasi City, Uttar Pradesh".

The erratum chapters and book have been updated with the changes.

The updated version of these chapters can be found at https://doi.org/10.1007/978-981-13-8421-9_12

https://doi.org/10.1007/978-981-13-8421-9_19 